\title{
Pharmacokinetics of metformin in the rat: Assessment of the effect of hyperlipidemia and evidence for its metabolism to guanylurea
}

\begin{tabular}{|r|l|}
\hline Journal: & Canadian Journal of Physiology and Pharmacology \\
\hline Manuscript ID & cjpp-2016-0329.R1 \\
\hline Manuscript Type: & Article \\
\hline Complete List of Authors: & $\begin{array}{l}\text { Gabr, Raniah; University of Alberta } \\
\text { El-Sherbeni, Ahmed; University of Alberta, } \\
\text { Ben-Eltriki, Mohamed; University of Alberta } \\
\text { El-Kadi, Ayman; University of Alberta, } \\
\text { Brocks, Dion; University of Alberta, }\end{array}$ \\
\hline Keyword: & $\begin{array}{l}\text { Metformin, Solute carrier transporters, Cytochrome P450, Renal clearance, } \\
\text { Liquid chromatography-mass spectrometry }\end{array}$ \\
\hline \multicolumn{2}{|c}{} \\
\hline
\end{tabular}

SCHOLARONE

Manuscripts 
Pharmacokinetics of metformin in the rat: Assessment of the effect of hyperlipidemia and evidence for its metabolism to guanylurea

Raniah Q. Gabr, Ahmed A. El-Sherbeni, Mohamed Ben-Eltriki, Ayman O. El-Kadi and Dion R. Brocks*

Faculty of Pharmacy and Pharmaceutical Sciences, University of Alberta, Edmonton, Alberta, Canada

Correspondence to:

Dion R. Brocks, Ph.D.

Professor and Associate Dean

Faculty of Pharmacy and Pharmaceutical Sciences

2-142 H Katz Group Centre for Pharmacy and Health Research,

University of Alberta

Edmonton, AB

Canada

T6G 2E1

E-mail: dbrocks@ualberta.ca

(780) 492-2953 FAX (780) 492-1217

Keywords: Poloxamer 407, biguanides, organic cation transporters, mass spectroscopy 


\begin{abstract}
Metformin pharmacokinetics are highly dependent upon organic cationic transporters. There is evidence of a change in its renal clearance in hyperlipidemic obese patients, and no information on its metabolic fate. To study some of these aspects, the influence of poloxamer 407 (P407)induced hyperlipidemia on metformin pharmacokinetics was assessed. Control and P407 treated adult male rats were administered $30 \mathrm{mg} / \mathrm{kg}$ metformin intravenously (iv). The pharmacokinetic assessments were performed at 2 time points, 36 and $108 h$, following the intraperitoneal dose of P407 $(1 \mathrm{~g} / \mathrm{kg})$. mRNA and protein expressions of cationic drug transporters were also measured. There was no evidence of a change in metformin pharmacokinetics after iv doses as a consequence of short term hyperlipidemia, and a change in transporter mRNA but not protein expression in the $108 h$ post-P407 treated rats. Urinary recovery of unchanged drug was high (> 90\%) but incomplete. Presumed metabolite peaks were detected in chromatograms of hepatocytes and microsomal protein spiked with metformin. Comparative chromatographic elution times and mass spectra suggested that one of the predominant metabolites was guanylurea. Hyperlipidemia by itself did not affect the pharmacokinetics of metformin. Guanylurea is a putative metabolite of metformin in rats.
\end{abstract}




\section{Introduction}

Lipoproteins are involved in the movement mobilization of lipids (triglycerides, cholesterol and phospholipids) between tissues and the blood, which serves as a conduit (Wasan et al. 2008). Hyperlipidemia (HL), a condition of abnormally high concentrations of serum lower density lipoproteins, is a key factor in the development of atherosclerosis and cardiovascular disease. In recent years, the impact of HL on the pharmacokinetic behavior of drugs has been assessed. Certain drugs, in particular those possessing higher $\log \mathrm{P}$ values, have the capability to sequester into or bind to lipoproteins. Thus HL can be associated with increased plasma binding and lower unbound fraction in plasma, with a reduction in overall drug volume of distribution (Vd) and possibly total body clearance (CL). In certain tissues, however, such binding has been observed for some drug as an increased tissue penetration, which has been attributed to the presence of lipoprotein receptors in those tissues and selective tissue uptake of drug-laden lipoproteins (Patel et al. 2009; Shayeganpour et al. 2008) and/or decrease in efflux transporter expression (Brocks et al. 2014). HL has also been associated with a decrease in expression and function of some cytochrome P450 (CYP) isoforms known to be involved in drug metabolism (Patel and Brocks 2009).

Metformin (MET) is an important treatment choice for type 2 diabetes, a disease associated with other hallmarks of cardiometabolic syndrome including obesity and HL. Metformin disposition in terms of absorption, distribution and renal excretion is highly dependent upon organic cation transport proteins. With respect to its elimination, MET is considered to be mostly excreted unchanged in the urine, although the precise amount has been the subject of some debate with ranges of 80 to $100 \%$ having been reported (Graham et al. 2011). The renal clearance (CLr) has been reported to be approximately $500 \mathrm{~mL} / \mathrm{min}$ in mostly lean humans. However, in a surgically 
untreated group of obese patients given metformin orally, the CLr was estimated to be considerably lower $(337 \mathrm{~mL} / \mathrm{min})$, and significantly lower than that in obese patients several months following bariatric surgery (461 mL/min) (Padwal et al. 2011).

This raises a question as to what might lead to a reduced metformin renal CL in obesity. The bariatric surgery patients in the previous study were age, gender and weight matched to the untreated obese group at the time of the metformin pharmacokinetic assessment. However there was one notable difference between the two patient groups, in that the surgically untreated obese patients had significantly higher concentrations of serum triglyceride and total cholesterol than did the bariatric surgical patients. Given the known influence of HL on drug disposition, this raises a question as to whether increased levels of lipoproteins can affect the transporters involved in the disposition of MET.

Obesity is a complex disease state that may be associated with inflammation and other conditions such as diabetes and cardiovascular disease in addition to hyperlipidemia. The single dose poloxamer 407 (P407) induced model of HL is an appropriate choice to assess for the influence of hyperlipidemia on the pharmacokinetics of drugs, as it is non-inflammatory and is not associated with cardiovascular disruption or diabetes. For this reason, we adopted its use to see if, like has been established for CYP, it could affect the solute carrier (SLC) proteins involved in metformin renal excretion and pharmacokinetics. Furthermore because there has been some debate over the extent of MET that is subject to urinary excretion (Graham et al. 2011), a special focus was placed on the urinary recovery of the drug in normolipidemic (NL) rats and the possible metabolic fate of MET in the rat.

\section{Methods}




\section{Chemicals}

Metformin $\mathrm{HCl}$ (>97\% purity) was purchased from Sigma-Aldrich (St. Louis, MO, USA). Nicotinamide adenine dinucleotide phosphate tetrasodium (NADPH), P407, fetal calf serum, collagenase, trypsin inhibitor, Percoll gradient, collagen, HEPES sodium salt, bovine serum albumin (BSA) and other general laboratory chemicals were purchased from Sigma-Aldrich (St. Louis, MO). Penicillin-streptomycin, insulin, dexamethasone phosphate, DME media, and trypsin were obtained from GIBCO, Invitrogen Corporation (Carlsbad, CA, USA). Heparin sodium injection, $1000 \mathrm{U} / \mathrm{mL}$ and $10000 \mathrm{U} / \mathrm{mL}$, were obtained from Leo Pharma Inc. (Thornhill, ON, Canada). TRIzol reagent was purchased from Invitrogen (Carlsbad, CA). High-Capacity cDNA Reverse Transcription Kit, SYBR Green SuperMix were purchased from Applied Biosystems (Foster City, CA). Real-time PCR primers were synthesized by Integrated DNA Technologies, Inc. (Coralville, IA) according to previously published sequences.

\section{Animals and induction of $H L$}

All study protocols involving rats were approved by the Institutional Animal Policy and Welfare Committee. Male Sprague-Dawley rats (Charles River, Quebec, Canada) with body weight ranging from 280 to $380 \mathrm{~g}$ (2-3 months age) were used. All rats were housed in temperaturecontrolled rooms with $12 h$ light per day. The animals were fed a standard rodent chow containing 4.5\% fat (Lab Diet巴 5001, PMI nutrition LLC, Brentwood, MO). Free access to food and water was permitted prior to the experiments.

The HL rats were injected $1 \mathrm{~g}$ P407/kg intraperitoneally (ip) as previously described under light isoflurane anesthesia. The NL control rats were injected equivalent volumes of normal saline. Metformin was administered $36 h$ later, or at $108 h$ to represent a longer duration of HL. 
Surgery, MET dosing and sample collection

The rats were allocated into three groups, saline-treated NL (controls), acute high lipoprotein concentration of short duration HL (36 $h$ after P407), and more sustained HL (108 $h$ after P407). The NL control group included 6 rats, whereas HL groups contained 6 rats for the short term HL and 8 rats for the longer term HL. The day before the experiment, the jugular veins of the rats were catheterized with a cannula under isoflurane anesthesia delivered by anesthetic machine as previously described (Hamdy and Brocks 2011). The cannula was filled with $100 \mathrm{u} / \mathrm{mL}$ heparin in saline then capped. After recovery, each rat was allowed to have free access to water but not food. The morning after surgery each rat was transferred to a metabolic cage (to facilitate sampling and urine collection) and after adaptation for approximately $30 \mathrm{~min}$ with free allowance to water, the rats were administered the intravenous (iv) doses of MET. Food was reintroduced ad libitum $2 h$ after the dose was administered.

The maximum human oral dose of MET is $2550 \mathrm{mg}(\sim 36 \mathrm{mg} / \mathrm{kg} / d)$ per day orally(Setter et al. 2003). Hence the metformin single dose level was chosen to be $30 \mathrm{mg} / \mathrm{kg}$. The jv route was used to afford $100 \%$ bioavailability, such that cumulative urinary excretion could be determined. The MET injectable solution was prepared in sterile saline for injection to provide a final concentration of $12.5 \mathrm{mg} / \mathrm{mL}$. Each dose was injected over $60 \mathrm{~s}$ via the jugular vein cannula, followed immediately by injection of $0.5 \mathrm{~mL}$ of saline. Serial blood samples $(0.15-0.25 \mathrm{~mL})$ were collected at $0.08,0.33,0.65,1,2,3,4,6,8,12$ and $24 h$ post-dose into polypropylene micro-centrifuge tubes. For the first sample, an initial $200 \mu \mathrm{L}$ volume of blood was discarded followed by the collection of the sample for analysis. Heparin in normal saline $(100 \mathrm{U} / \mathrm{mL})$ was used to flush the cannula after each collection of blood. Plasma was separated by centrifugation of the blood at $2500 \mathrm{~g}$ for $3 \mathrm{~min}$. Urine was collected at the periods 0-3, 3-6, 6-12 and 12-24 $h$, 
volume measured and an aliquot saved. All samples were kept at $-20^{\circ} \mathrm{C}$ until assayed for MET using a validated high performance liquid chromatographic method (Gabr et al, 2010). The concentration of potassium phosphate used in the mobile phase was $25 \mathrm{mM}$.

Effect of HL expression of MET-related urinary excretion transporters

Kidneys were collected from a satellite group of control rats, and rats 36 or $108 h$ after P407 injection under anesthesia. The tissue samples were directly frozen in liquid nitrogen and kept at $-80^{\circ} \mathrm{C}$ until analysed for mRNA and protein.

Real time PCR

Total RNA was isolated from the frozen kidney tissues using TRIzol reagent (Invitrogen) according to the manufacturer's instructions and quantified by measuring the absorbance at 260 nm. First strand cDNA synthesis was performed by using the High-Capacity cDNA reverse transcription kit (Applied Biosystems, Foster City CA) according to the manufacturer's instructions.

Quantitative analysis of mRNA expression was performed by real-time polymerase chain reaction by subjecting the resulting cDNA to PCR amplification in 96-well optical reaction plates using the ABI Prism 7500 System (Applied Biosystems). The $25 \mu \mathrm{L}$ reaction mix contained $0.1 \mu \mathrm{L}$ of $10 \mu \mathrm{M}$ forward primer, $0.1 \mu \mathrm{L}$ of $10 \mu \mathrm{M}$ reverse primer, $12.5 \mu \mathrm{l}$ of SYBR Green Universal Mastermix, $11.05 \mu \mathrm{L}$ of nuclease-free water and $1.25 \mu \mathrm{L}$ of cDNA sample. Sense and anti-sense primer sequences for Oct1, Oct2, Mate1 and glyceraldehyde-3-phosphate dehydrogenase (Gapdh) are provided in Table 1). The thermocycling conditions were initiated at 
$95^{\circ} \mathrm{C}$ for $10 \mathrm{~min}$, followed by 40 PCR cycles of denaturation at $95^{\circ} \mathrm{C}$ for $15 \mathrm{~s}$ and annealing/extension at $60^{\circ} \mathrm{C}$ for $1 \mathrm{~min}$. Melting curve for the dissociation stage was performed by the end of each cycle to ascertain the specificity of the primers and the purity of the final PCR product.

The real-time PCR data were analyzed using the relative gene expression (i.e., $\Delta \Delta \mathrm{CT}$ ) method, as described in Applied Biosystems User Bulletin No. 2. The data are presented as the foldchange in gene expression normalized to the endogenous reference gene GAPDH and relative to a calibrator. The mRNA from NL rats was used as the calibrator to measure the relative change in gene expression caused by HL.

\section{Protein separation and Western blot analysis}

Rat kidney biopsies (200 mg) were homogenized in $1 \mathrm{~mL}$ of homogenizing buffer $(250 \mathrm{mM}$ sucrose, $10 \mathrm{mM}$ HEPES, and $10 \mathrm{mM}$ Tris-HCL, $\mathrm{pH}$ 7.4) containing $0.1 \mathrm{mM}$ phenylmethylsulfonyl fluoride (PMSF) using electric tissue grinder. Differential centrifugation was used to obtain a crude membrane fraction. In brief, the kidney homogenates were centrifuged at $9000 \mathrm{~g}$ for $10 \mathrm{~min}$ at $4^{\circ} \mathrm{C}$. Then, the supernatant was spun at 33,000 $\mathrm{g}$ for $60 \mathrm{~min}$ at $4^{\circ} \mathrm{C}$. Finally, the resulting pellet was suspended in phosphate-buffered saline containing 0.1 mM PMSF. Samples were then sonicated on ice for $10 \mathrm{~s}$ to ensure homogeneity (Naud et al, 2001) (Naud et al. 2011). Protein concentrations were determined, using BSA as a reference protein. Aliquots were stored at $-80^{\circ} \mathrm{C}$ until analysis.

Protein $(50 \mu \mathrm{g})$ from each rat kidney was denatured by diluting in $2 \mathrm{X}$ loading buffer and heating for $20 \mathrm{~min}$ at $36^{\circ} \mathrm{C}$. Then protein in each denatured sample was separated by $7 \%$ SDSpolyacrylamide gel electrophoresis (SDS-PAGE) and transferred to a polyvinylidene difluoride 
(PVDF) membrane. Thereafter, membranes were blocked for $24 h$ at $4^{\circ} \mathrm{C}$ in blocking buffer containing 5\% skim milk powder and $0.5 \%(\mathrm{v} / \mathrm{v})$ Tween-20 in tris-buffered saline solution (TBS; $0.15 \mathrm{M}$ sodium chloride, $3 \mathrm{mM} \mathrm{KCl}, 25 \mathrm{mM}$ Tris-base). Thereafter, the blocking solution was removed and the blots were rinsed three times in a wash buffer $(0.1 \%$ Tween-20 in Tris-buffered saline). Then, membranes were incubated with primary antibodies overnight at $4^{\circ} \mathrm{C}$. The primary antibody solutions were removed and blots were rinsed three times, followed by incubation with secondary antibody for $2 h$ at room temperature. Rinsing was then applied to remove the extra secondary antibody. Finally, the protein bands were detected using enhanced chemiluminescence. Protein band intensities (relative to $\beta$-actin bands intensity) were quantified using Image-J software (National Institutes of Health, Bethesda, MD, http://rsb.info.nih.gov/ij.).

\section{Isolated rat hepatocytes}

Male NL rats (300-400 g) were housed in cages and provided water and food ad libitum up to the time of hepatocyte isolation. The isolation of hepatocytes was performed as previously described (Brocks et al. 2014) following a two-step liver perfusion procedure. Cells were placed in Dulbecco's Modified Eagle Medium (DMEM) supplemented with 10\% NL rat serum and antibiotics (penicillin/streptomycin, 1\%). After viability assessments cells were added at 0.3 million per well in $300 \mu \mathrm{L}$ of cell suspension and the plates were incubated for $6 h$ at $37^{\circ} \mathrm{C}$ in a humidifier with $95 \% \mathrm{O}_{2}$ and $5 \% \mathrm{CO}_{2}$. After $6 h$, the media containing the dead cells was removed and cells were washed twice with $1 \mathrm{X}$ PBS. The media was replaced by DMEM without added serum.

A $10 \mu \mathrm{L}$ volume of MET stock solution $(2.5 \mu \mathrm{g} / \mu \mathrm{L})$ in double distilled water was added to 25 mL DMEM to provide a final MET concentration of $1000 \mathrm{ng} / \mathrm{mL}$. Metformin was co-incubated 
with hepatocytes at a concentration of $1000 \mathrm{ng} / \mathrm{mL}$ alone or with either $\beta$-glucuronidase 1200 Roy $U / \mathrm{mL}$ or sulfatase 150 Fishman $U / \mathrm{mL}$ for 0,12 and $24 h$ ( $n=6$ wells for each time point) (Donato et al. 2004). At the various time points, the hepatocyte incubations were terminated by addition of $0.2 \mathrm{~mL}$ water. To each well, $30 \mu \mathrm{L}$ of internal standard (Gabr et al. 2010) were added then the well contents were collected and kept at $-20^{\circ} \mathrm{C}$ until assayed.

\section{Exposure of MET to isolated rat microsomes}

Hepatic microsomal protein from NL male rats were isolated as previously described (ElSherbeni and El-Kadi 2014). The total protein concentrations were determined using the Lowry method. The microsomal residues were reconstituted with ice cold sucrose to concentrations of $1 \mathrm{mg}$ protein/mL. Incubation was performed in incubation buffer $(3 \mathrm{mM} \mathrm{MgCl}$ hexahydrate dissolved in $100 \mathrm{mM}$ potassium phosphate buffer $\mathrm{pH} 7.4$ ) at $37^{\circ} \mathrm{C}$ in a shaking water bath. One set of tubes contained microsomal protein only. The second set contained microsomal protein with $(100 \mu \mathrm{g} / \mathrm{mL})$ MET. The third set contained $100 \mu \mathrm{g} / \mathrm{mL}$ MET alone with media but no protein. Each set consisted of five tubes. The total volume of microsomal incubates was 1 $\mathrm{mL} /$ tube of the buffer. The reaction was initiated by the addition of $1 \mathrm{mM}$ NADPH (final concentration $2 \mathrm{mM}$ ) for $30 \mathrm{~min}$ at $37^{\circ} \mathrm{C}$ in a shaking water bath, after which the reaction was terminated by the addition of $300 \mu \mathrm{L}$ ice-cold acidified acetonitrile. Aliquots of $100 \mu \mathrm{L}$ were subjected to extraction and analysis by HPLC-UV.

In another experiment, MET was incubated with $1 \mathrm{mg} / \mathrm{mL}$ microsomal protein from pooled male rat liver microsomes for 0,20 or $45 \mathrm{~min}$, with the same conditions as expressed above. The reaction was initiated by the addition of $2 \mathrm{mM} \mathrm{NADPH}$ (final concentration) and terminated by the addition of $600 \mu \mathrm{L}$ ethanol to the $300 \mu \mathrm{L}$ incubation mixture. The samples were centrifuged 
at $14,000 \mathrm{rpm}$ for $15 \mathrm{~min}$ at $0^{\circ} \mathrm{C}$. Thereafter, the supernatants were evaporated to dryness and, then, reconstituted in $100 \mu \mathrm{L}$ of $20 \%$ ammonium hydroxide in water and subjected to LC-MS.

Separation and collection of presumed metabolite from microsomal incubates

Based on the chromatographic pattern of microsomal incubates a fractional separation was performed to isolate the chromatographic peak of interest using repeated HPLC injections. Media from the microsomal incubations was extracted (Gabr et al. 2010). To afford separation and allow for subsequent mass spectrometric analysis, reverse phase chromatography was performed using a modified mobile phase that consisted of acetonitrile and water (17:83) adjusted to $\mathrm{pH} 6.5$ using ammonium hydroxide. The column, flow rate and detection wavelengths were as for the regular assay (Gabr et al. 2010). Solution of structurally similar compounds to MET, guanylurea and biuret, were also injected as possible metabolic products.

Mass spectrum characterization

The targeted eluent fraction corresponding to the main presumed metabolite formed from the 0.1 $\mathrm{mg} / \mathrm{mL}$ MET-microsomal incubations was collected from several HPLC runs. The pooled specimens were vacuum concentrated at room temperature, then and subjected to mass spectrometry. The mass analysis was carried out using a single quadrupole system (Waters Micromass ZQ $\mathrm{Q}^{\mathrm{TM}} 4000$ spectrometer equipped with electron spray ionization (ESI) source. The mass detection was through a direct infusion of the collected eluent and pure $2 \mu \mathrm{g} / \mathrm{mL}$ analyte standard solutions into the detector. Each of the peaks was characterized using selective ion recorder (SIR) in positive ion mode. The other parameter settings were gas source temperature of $140^{\circ} \mathrm{C}$, capillary voltage of $3.45 \mathrm{kV}$ and cone voltage of $15 \mathrm{~V}$. The gas flow of desolvation and 
cone gas flow were set at 550 and $120 \mathrm{~L} / \mathrm{h}$, respectively. These conditions were found to be optimal for ionization of MET, guanylurea and biuret.

The separation of metformin and its metabolite from the $1 \mathrm{mg} / \mathrm{mL}$ MET-microsomal incubation was also directly performed using LC-ESI-MS. The compounds were eluted with a mobile phase of $10 \%$ acetonitrile in water with $40 \mathrm{mM}$ ammonium carbonate $(\mathrm{pH}$ 8) at a flow rate of 0.2 $\mathrm{mL} / \mathrm{min}$, using a C18 column (Alltima HP, $250 \times 2.1 \mathrm{~mm}$ ). The mass spectrometer was run in positive ionization mode with an ion scan from $\mathrm{m} / \mathrm{z}$ of 100 to 135 . The nebulizer gas was acquired from an in house high purity nitrogen source. The temperature of the source was set at $150^{\circ} \mathrm{C}$, and the capillary and cone voltage were $3.5 \mathrm{kV}$ and $20 \mathrm{~V}$, respectively.

\section{Pharmacokinetic and statistical analysis}

Non-compartmental methods were used to characterize the pharmacokinetic properties. The terminal elimination rate constant $\left(\lambda_{z}\right)$ was calculated by subjecting the plasma concentrations in the terminal phase to linear regression analysis. The $\mathrm{t}^{1} \frac{2}{2}$ was calculated by dividing 0.693 by $\lambda \mathrm{z}$. The $\mathrm{AUC}_{0-24}$ of MET (up to $24 h$ post dose) was calculated using the combined linear and loglinear trapezoidal rule and this was added to the last measured concentration divided by $\lambda \mathrm{z}$ to determine $\mathrm{AUC}_{0-\infty}$. The concentration at time $0 h$ after iv dosing was estimated by back extrapolation of the initial log-transformed concentrations to time 0 . The total CL was calculated as the quotient of dose to $\mathrm{AUC}_{0-\infty}$ and the steady state $\mathrm{Vd}(\mathrm{Vdss})$ as $\mathrm{CL} \times \mathrm{AUMC} / \mathrm{AUC}$, where AUMC is the area under the first moment plasma concentration vs. time curve, from time of dosing to infinity. The mean residence time (MRT) was determined as the quotient of AUMC to AUC. The $\mathrm{CL}_{\mathrm{r}}$ was calculated as the product of urinary recovery and $\mathrm{CL}$, and nonrenal $\mathrm{CL}$ $\left(\mathrm{CL}_{\mathrm{nr}}\right)$ as the difference of $\mathrm{CL}_{\mathrm{r}}$ from CL. Between-group differences in the arithmetic means of 
continuous baseline variables were analyzed using paired Student's $t$-test (if the normality assumption passed) or a Mann-Whitney test (if the normality assumption failed).

All compiled data were expressed as mean \pm SD unless otherwise indicated. Student's $t$-test were performed using Microsoft Excel 2013 (Redmond WA). The level of significance in all statistical testing was set at $\alpha=0.05$. Bonferroni correction was applied to the multiple comparisons between pharmacokinetic parameters of control and HL groups.

\section{Results}

After iv administration of $30 \mathrm{mg} / \mathrm{kg}$ of MET, HL was found not to cause any significant change in MET pharmacokinetics whether the dose was administered at 36 or $108 h$ from the time of injection of P407 (Table 2, Figure 1). This was reflected in the pharmacokinetic parameters, none of which was found to differ from the NL group. Two extra rats were included in the HL $108 h$ group of rats, because there was some loss of urine during collection (those rats were excluded from CLr calculations). It was found that from 92 to $100 \%$ of the MET dose was eliminated unchanged via urinary excretion, and CLr accordingly accounted for the majority of the measured CL in all groups.

\section{Expression of rat OCT1, OCT2 and MATE1 transporters in kidney}

There were no significant differences noted between control and $36 h$ post-P407 in the measured kidney mRNA of Oct1, Oct 2 or Matel. At $108 h$ after injection of P407 there were significant decreases in mRNA of $48 \%$ and $66 \%$, respectively, for Oct1 and Mate1 respectively (Figure 2). 
The CV was close to $30 \%$ for both test groups in these mRNA. However, HL did not change the mRNA expression of Oct-2 where the test group had high variability (CV\% $=57)$ (Figure 2).

With respect to protein, although a trend was apparent (each mean being numerically lower in value) for the transporters at $108 h$ after P407 compared to NL controls, there were no statistically significant differences present in protein concentration of any of the three examined kidney transporters in HL (36 or $108 \mathrm{~h}$ ) and control animals.

Assessment of MET metabolism

Chromatograms of MET incubated hepatocytes

Immediately after addition of MET into wells containing hepatocytes, there was no appearance of unusual peaks, only the peak conforming to MET at $11.6 \mathrm{~min}$. However, with time (12 and $24 \mathrm{~h}$ ) a new peak appeared, which eluted just before MET (at $\sim 10.5 \mathrm{~min}$ ). In addition, the peak at $4.8 \mathrm{~min}$, which also appeared in the media-only blank sample, was noticeably higher after 12 to $24 h$ MET-hepatocyte incubations (Figure 3). The incubation of hepatocyte samples with Phase II hydrolyzing enzymes caused no increase in the concentrations of MET.

\section{Incubation of MET with rat microsomal protein}

Upon the incubation of $100 \mu \mathrm{g} / \mathrm{mL}$ MET for $30 \mathrm{~min}$ with isolated rat microsomes (1 $\mathrm{mg}$ protein $/ \mathrm{mL}$ ), two peaks became clearly evident in the chromatograms of extracted samples which were not present in the chromatograms of the blank microsomes or drug injected alone. These coincided with the observations of the peaks noticed in the hepatocyte incubations, except here the peak eluting at 4.8 min became more apparent because it was not present in the blank microsomal mixture. 
Subsequently other incubations were extracted and the pooled residues reconstituted in methanol. This was then injected into a modified mobile phase free of LC-MS incompatible additives (to facilitate possible evaporation/concentration, fractional separation by HPLC/UV and subsequent mass characterization). Using the modified mobile phase (Figure 3, middle panel), it was observed that a presumed metabolite peak eluted at nearly the same retention time (4.8 $\mathrm{min})$ as was the case for the mobile phase (Gabr et al. 2010) used in the microsomal and hepatocyte incubation experiments (Figure 3, top and middle panels). Upon direct injection of some compounds closely related to MET with the modified mobile phase, biuret yielded an elution peak (Figure 3, bottom panel) that did not match that of the unknown peak. However, an injection of guanylurea yielded an elution peak that coincided with that of the unknown peak (Figure 3, bottom panel). Fractional separation was then performed to collect that peak of interest for subsequent mass spectrometric characterization.

Spectral analysis of the primary isolated presumed metabolite

A mass spectral analysis of the isolated eluted peak of interest (at $4.8 \mathrm{~min}$, Figure 3, bottom panel) from the HPLC run was performed. The largest ion had $\mathrm{m} / \mathrm{z}$ ratio of 103 , with a smaller one of $\mathrm{m} / \mathrm{z}$ 104.9. MET in contrast had an $\mathrm{m} / \mathrm{z}$ ratio of 129.9 . Guanylurea gave a large ion with $\mathrm{m} / \mathrm{z}$ ratio of 103 , which precisely matched that of the largest $\mathrm{m} / \mathrm{z}$ ratio in the collected microsomal incubation fraction (Figure 4). This suggested that the main component in the eluent fraction collected from the HPLC injection was guanylurea.

The smaller peak of $105 \mathrm{~m} / \mathrm{z}$ suggested the possibility of being a reduced form of guanylurea, possibly diaminomethylurea. To explore this possibility, the reducing agent, sodium borohydride (40 mg), was added to $2 \mathrm{~mL}$ of guanylurea $(10 \mathrm{mg} / \mathrm{mL})$ in absolute ethanol at $-20^{\circ}$ (Hubert et al. 
1975). For the first $6 h, 1 \mu \mathrm{L}$ of $\mathrm{HCl}(2 \mathrm{~N})$ was added every $15 \mathrm{~min}$ to the reaction mixture, vortexed, then re-incubated at $-20^{\circ} \mathrm{C}$. After $24 h$, the excess of sodium borohydride was removed by the addition of $20 \mu \mathrm{L}$ concentrated $\mathrm{HCl}$. At $0,15 \mathrm{~min}, 30 \mathrm{~min}$, then $1,2,3,6$ and $24 h, 10 \mu \mathrm{L}$ of the reaction mixture was diluted in $1 \mathrm{~mL}$ absolute ethanol, and directly infused in the mass spectrometer (Waters Micromass ZQ 4000 spectrometer), using a flow rate of $40 \mu \mathrm{L} / \mathrm{min}$, source temperature of $140^{\circ} \mathrm{C}$, capillary and cone voltages of $3.5 \mathrm{kV}$ and $20 \mathrm{~V}$, respectively. There was no noticeable appearance of a peak at m/z 105 under these reducing conditions.

In the second experiment in which the incubate was injected on a C18 column, the LC-MS chromatogram showed no peak at $5 \mathrm{~min}$ in the $0 \mathrm{~h}$ incubation of MET with microsomal protein. After 30 and 45 min incubation of MET with the microsomal protein and cofactors, there was an appearance and growth of a peak at 5 min in the chromatograms which, as in the HPLC-UV run (Figure 3 bottom panel), coincided with the elution time of guanylurea (Figure 5).

\section{Discussion}

Profound changes can occur in the pharmacokinetics of drugs in the presence of P407-induced HL. Most of these drugs are known to bind extensively $(>70 \%)$ to plasma proteins (Brocks et al. 2006; Brocks and Wasan 2002; Choi et al. 2014; Kobuchi et al. 2011; Lee et al. 2011, 2012a; Lee et al. 2012c; Shayeganpour et al. 2005; Sugioka et al. 2009). Hyperlipidemia induced by P407 is also known to cause a downregulation in the expression of several CYP isoforms in liver of male rats, including CYP3A1/2 and CYP2C11, and decrease in mRNA of several proteins involved in drug transport and metabolism (Brocks et al. 2013; Shayeganpour et al. 2008). These changes in protein expression may account for alterations in the pharmacokinetics of drugs that 
are intrinsically less highly bound (Lee et al. 2012b) or in which the unbound fraction of drug is not affected by the presence of HL (Choi et al. 2014; Lee et al. 2012c).

Metformin is negligibly bound to plasma proteins and minimally metabolized, but is a major substrate for SLC transporters including Oct1/2 and Mate1 isoforms, which are known to be involved in the renal secretion of metformin in rats and humans (Graham et al. 2011; Kimura et al. 2005; Komazawa et al. 2013; Ma et al. 2015). The data show that at $36 h$ post-P407, the concentrations of serum lipids are at levels far exceeding what would be expected in human serum. By $108 h$ after administration, those lipid levels are more in line with what might be seen in line with HL patients. In neither case though was P407 associated with a change in MET concentrations. In the $108 h$ group of rats there was some decrease in the mRNA of Octl and Mate1, although no changes were noted in the corresponding protein concentrations (Figure 2). The results might suggest that the apparently lower MET CLr in obese humans is not due to HL alone, but rather to some other aspect of obesity, perhaps inflammation, which is not associated with the P407 model of HL(Chaudhary and Brocks 2013).

The data raised other issues in relation to MET pharmacokinetics in the rat. Although there has been some uncertainty as to the precise extent of urinary excretion of MET in humans, it is generally considered to be the predominant pathway of elimination with $80-100 \%$ recovery being reported, with a minor degree of metabolism (Beckmann 1968; Graham et al. 2011). On the other hand, there have been recent reports suggesting that MET is appreciably metabolized in the rat. In a series of papers it was suggested that only 50-67\% (Lee et al. 2008) of an iv dose of MET is excreted via the urine in male Sprague-Dawley rats, values appreciably lower than reported in humans (Choi et al. 2008a,b,c, Choi et al. 2007a,b, 2010a; Choi and Lee 2006, 2012). However some of these papers by the same group of investigators found higher recoveries $(78 \%$ over $24 h$ 
(Choi et al. 2006) and 79\% over $48 h$ (Choi et al. 2010)) in rat urine, values nearer those reported in humans. In all cases the rats had been administered the same dose of MET, $100 \mathrm{mg} / \mathrm{kg}$. In contrast, in our rats we attained a recovery in urine ranging from $92 \%$ to complete (Table 2 ). The maximum therapeutic dose of MET is $2 \mathrm{~g}$ per day, or approximately $30 \mathrm{mg} / \mathrm{kg}$ as given to our rats. In contrast, those rats in which the proportion of nonrenal CL being upwards of $50 \%$ of total CL were given higher iv doses of $100 \mathrm{mg} / \mathrm{kg}$. Compared to our AUC and estimates of $\mathrm{CL}_{\mathrm{r}}$ to those reports using the higher doses there is some suggestion for saturation of CL with increased dose. However, in one of the abovementioned studies comparing 50, 100 and $200 \mathrm{mg} / \mathrm{kg}$ doses (Choi et al. 2006) no evidence of saturation in urinary recovery was observed.

Aside from the extent of urinary excretion, based on the results of rat liver and intestinal microsomal incubations it has been demonstrated that MET concentrations could be lowered by apparent metabolism in vitro (Choi et al. 2010a,b, Choi and Lee 2012). No evidence of what it is possibly metabolized to in mammals has been published to date, however. In examining some chromatograms from our previous human trial and also from the rats given MET in this study, some small peaks were noticed eluting before MET, that were MET-related because they were not visible in urine of humans not given MET. Some of these same peaks were found in rat hepatocytes exposed to MET and to microsomal protein isolated from NL rat livers (Figure 3).

MET is the most widely used of all antidiabetic drugs and its dose levels are in the gram range, being amongst the highest of all clinically used drugs. Hence, although the percentage of metabolism is reportedly small, even 10 to $20 \%$ potential metabolism in humans as has been suggested by some authors, could potentially generate appreciable body exposure to metabolite. Guanylurea was recently reported to be a bacterial breakdown product of MET in sewage (Trautwein and Kummerer 2011). Using the modified mobile phase we found a microsomal 
product peak we had fractionally collected from the HPLC column eluent to precisely co-elute with guanylurea. Further support for guanylurea as a metabolic candidate was provided in the mass spectrographic patterns where the predominant ion of $\mathrm{m} / \mathrm{z}$ ratio in the collection fraction matched that of guanylurea. The LC-MS tracings of injected microsomal incubate and separation through a C18 column further supported the existence of guanylurea as a metabolite of MET. The possibility of the less prevalent ion at $104.9 \mathrm{~m} / \mathrm{z}$ seems unlikely to be a reduced microsomal product of guanylurea because it did not appear when guanylurea was exposed to the reducing agent $\mathrm{NaBH}_{4}$. The toxicological or pharmacological relevance of guanylurea as a metabolite of metformin is unknown, as there is a lack of data in the literature(ter laak and Baken 2014).

In conclusion, $\mathrm{HL}$ induced using a single dose of $\mathrm{P} 407$ had no influence on the pharmacokinetics of MET. Although there was some change in mRNA of two transporters involved in MET transport, it did not translate into a change in protein expression within $4.5 \mathrm{~d}$ of the dose of P407. Although urinary recovery in the rat was nearly complete after iv doses of $30 \mathrm{mg} / \mathrm{kg}$, we were able to detect the presence of small quantities of MET-related metabolite peaks in chromatograms of urine, hepatocytes and microsomal incubations. Guanylurea was identified to be a putative metabolite of MET in the rat.

Acknowledgements: RQG and AAE were recipients of an Egyptian Government Scholarship. AAE was also funded by an Alberta Innovates-Health Solutions studentship. MB was funded by a Libyan Government scholarship. 


\section{Legend to figures:}

Figure 1: Mean plasma concentration vs. time plots of MET after intravenous administration of $30 \mathrm{mg} / \mathrm{kg}$ as iv doses to normolipidemic (NL) or hyperlipidemic (HL) rats.

Figure 2: Effect (mean $\pm \mathrm{SD}$ ) of HL after $108 h$ ip injection of $\mathrm{P} 407$ on the mRNA and protein expression of rat kidney OCT1, OCT2 and MATE1 ( $n=4$ /group). Solid bars indicate control NL rats, cross hatched bars indicate treatment HL rats. Significant differences of HL from NL are denoted by *.

Figure 3. Top panel: Effect of hepatocytes on MET metabolism after exposure to $1000 \mathrm{ng} / \mathrm{mL}$ MET. Representative HPLC-UV chromatograms are depicted for a) hepatocyte-free media for 24 $h, \mathrm{~b})$ hepatocyte-free media containing $1000 \mathrm{ng} / \mathrm{mL}$ MET for $24 h$, and hepatocytes exposed to MET for c) $0 h$, d) $12 h$, and e) $24 h$. Middle panel: Chromatogram depicting a) MET-free microsomal protein, b) MET in buffer without microsomal protein, and c) microsomal incubation with MET $100 \mu \mathrm{g} / \mathrm{mL}$ for $30 \mathrm{~min}$. Lower panel: Chromatograms showing direct injection of standard solutions of guanylurea $(1 \mu \mathrm{g} / \mathrm{mL})$, biuret $(1 \mu \mathrm{g} / \mathrm{mL})$ and MET $(50 \mathrm{ng} / \mathrm{mL})$ and the collected eluent of the peak eluting at $4.8 \mathrm{~min}$ in the microsomal incubation using the modified mobile phase. The blank is the extracted microsomal media without addition of MET.

Figure 4: Mass spectra and chemical structures, from top down, MET-metabolite eluent fraction, guanylurea, biuret and MET. All compounds were dissolved or reconstituted in double distilled water containing $1 \%$ formic acid. The major ion of m/z 103 matched that of guanylurea.

Figure 5: Mass spectral chromatograms of injection of MET after exposure to rat microsomal protein for 0,20 and $45 \mathrm{~min}$ (ion scan from m/z 100 to 135.). The MET eluted at 10 min under these conditions. A peak appeared with progression of incubation times at 5 min, which corresponded with the elution time of guanylurea (indicated as control injection containing guanylurea and metformin standards in the same sample). 
Table 1: Sequences of rat primers used for real time PCR analysis

\begin{tabular}{|l|c|c|}
\hline Gene & Sense primer & Anti-sense primer \\
\hline $\begin{array}{l}\text { Octl(Shi et al. } \\
\text { 2008) }\end{array}$ & $\begin{array}{c}\text { TCC TGC TGA CCT GAA GAT } \\
\text { GCT }\end{array}$ & $\begin{array}{c}\text { GAA CAG GTC GGC AAA CGA } \\
\text { TAG }\end{array}$ \\
\hline $\begin{array}{l}\text { Oct2(Kristufek } \\
\text { et al. 2002) }\end{array}$ & $\begin{array}{c}\text { GCT TGG GTA GAA TGG GCA } \\
\text { TC }\end{array}$ & GTG AGG TTG GTT TGT GTG GG \\
\hline $\begin{array}{l}\text { Mate1(Kajiwara } \\
\text { et al. 2007) }\end{array}$ & $\begin{array}{c}\text { CAC ACT GGC AAT TGC GGT } \\
\text { TA }\end{array}$ & CTT CAA GTT CTG GCT CCC GT \\
\hline $\begin{array}{l}\text { Gapdh(Takizawa } \\
\text { et al. 2005) }\end{array}$ & GGC CAA GGT CAT CCA TGA & TCA GTG TAG CCC AGG AGG \\
\hline
\end{tabular}


Table 2: Pharmacokinetics (mean \pm SD) of MET in normolipidemic (NL) and hyperlipidemic (HL) rats given $30 \mathrm{mg} / \mathrm{kg}$ of MET intravenously.

\begin{tabular}{|l|c|c|c|}
\hline \multirow{2}{*}{ Parameter } & \multicolumn{3}{|c|}{ Treatment group (n) } \\
\cline { 2 - 4 } & NL (6) & HL 36 $\boldsymbol{h}(\mathbf{6})$ & HL 108 $\boldsymbol{h}$ (8) \\
\hline$A U C_{0-\infty} \mu \mathrm{g} \cdot \mathrm{h} / \mathrm{mL}$ & $17.7 \pm 4.33$ & $13.4 \pm 3.75$ & $13.9 \pm 2.58$ \\
\hline$C L, \mathrm{~mL} / \mathrm{min} / \mathrm{kg}$ & $29.5 \pm 6.02$ & $39.7 \pm 9.71$ & $37.2 \pm 6.75$ \\
\hline$C L_{r}, \mathrm{~mL} / \mathrm{min} / \mathrm{kg}$ & $27.2 \pm 5.66$ & $36.4 \pm 11.5$ & $35.3 \pm 5.87^{\mathrm{a}}$ \\
\hline$C L_{n r}, \mathrm{~mL} / \mathrm{min} / \mathrm{kg}$ & $2.43 \pm 2.02$ & $3.55 \pm 5.48$ & $0.0659 \pm 0.161^{\mathrm{a}}$ \\
\hline$V d_{s s}, \mathrm{~L} / \mathrm{kg}$ & $2.32 \pm 1.38$ & $2.76 \pm 1.22$ & $1.73 \pm 0.755$ \\
\hline$M R T, h$ & $1.26 \pm 0.599$ & $1.16 \pm 0.440$ & $0.761 \pm 0.252$ \\
\hline$t_{1 / 2}, h$ & $4.88 \pm 2.52$ & $3.01 \pm 1.12$ & $2.77 \pm 0.698$ \\
\hline Urinary recovery, \% & $92.2 \pm 7.09$ & $92.2 \pm 15.0$ & $102 \pm 3.24^{\mathrm{a}}$ \\
\hline${ }^{2}$ based on 6 rats (urine was lost from 2 rats) \\
\hline \multicolumn{4}{|l}{} \\
\hline
\end{tabular}




\section{References}

Beckmann, R. 1968. The fate of biguanides in man. Ann. N. Y. Acad. Sci. 148(3): 820-832.

Brocks, D.R., Ala, S., and Aliabadi, H.M. 2006. The effect of increased lipoprotein levels on the pharmacokinetics of cyclosporine A in the laboratory rat. Biopharm. Drug Dispos. 27(1): 7-16.

Brocks, D.R., Chaudhary, H.R., Ben-Eltriki, M., Elsherbiny, M.E., and El-Kadi, A.O. 2014. Effects of serum lipoproteins on cyclosporine A cellular uptake and renal toxicity in vitro. Can. J Physiol. Pharmacol. 92(2): 140-148.

Brocks, D.R., Hamdy, D.A., Ben-Eltriki, M., Patel, J.P., and Ao, S.E.-K. 2013. Effect of rat serum lipoproteins on mRNA levels and amiodarone metabolism by cultured primary rat hepatocytes. J. Pharm. Sci. 102(1): 262-270.

Brocks, D.R., and Wasan, K.M. 2002. The influence of lipids on stereoselective pharmacokinetics of halofantrine: Important implications in food-effect studies involving drugs that bind to lipoproteins. J. Pharm. Sci. 91(8): 1817-1826.

Chaudhary, H.R., and Brocks, D.R. 2013. The Single Dose Poloxamer 407 Model of Hyperlipidemia; Systemic Effects on Lipids Assessed Using Pharmacokinetic Methods, and its Effects on Adipokines. J. Pharm. Pharm. Sci. 16(1): 65-73.

Choi, M.R., Kwon, M.H., Cho, Y.Y., Choi, H.D., Kim, Y.C., and Kang H.E. 2014. Pharmacokinetics of tolbutamide and its metabolite 4-hydroxy tolbutamide in poloxamer 407induced hyperlipidemic rats. Biopharm. Drug Dispos. 35(5): 264-274.

Choi, Y.H., Kim, S.G., and Lee, M.G. 2006. Dose-independent pharmacokinetics of metformin in rats: Hepatic and gastrointestinal first-pass effects. J. Pharm. Sci. 95(11): 2543-2552. 
Choi, Y.H., and Lee, M.G. 2006. Effects of enzyme inducers and inhibitors on the pharmacokinetics of metformin in rats: involvement of CYP2C11, 2D1 and 3A1/2 for the metabolism of metformin. Br. J. Pharmacol. 149(4): 424-430.

Choi, Y.H., Lee, I., and Lee, M.G. 2007a. Effects of bacterial lipopolysaccharide on the pharmacokinetics of metformin in rats. Int. J. Pharm. 337(1-2): 194-201.

Choi Y.H., Lee I. and Lee M.G. 2007b. Effects of water deprivation on the pharmacokinetics of metformin in rats. Biopharm. Drug Dispos. 28(7): 373-383.

Choi, Y.H., Chung, S.J., and Lee, M.G. 2008a. Pharmacokinetic interaction between DA-8159, a new erectogenic, and metformin in rats: competitive inhibition of metabolism via hepatic CYP3A1/2. Br. J. Pharmacol. 153(7): 1568-1578.

Choi, Y.H., Lee, D.C., Lee, I., and Lee, M.G. 2008b. Changes in metformin pharmacokinetics after intravenous and oral administration to rats with short-term and long-term diabetes induced by streptozotocin. J. Pharm. Sci. 97(12): 5363-5375.

Choi Y.H., Lee I. and Lee M.G. 2008c. Effects of cysteine on metformin pharmacokinetics in rats with protein-calorie malnutrition: partial restoration of some parameters to control levels. J. Pharm. Pharmacol. 60(2): 153-161.

Choi, Y.H., Lee, I. and Lee, M.G. 2010a. Slower clearance of intravenous metformin in rats with acute renal failure induced by uranyl nitrate: contribution of slower renal and non-renal clearances. Eur. J. Pharm. Sci. 39(1-3): 1-7.

Choi, Y.H., Lee, U., Lee, B.K., and Lee, M.G. 2010b. Pharmacokinetic interaction between itraconazole and metformin in rats: competitive inhibition of metabolism of each drug by each other via hepatic and intestinal CYP3A1/2. Br. J. Pharmacol. 161(4): 815-829. 
Choi, Y.H., and Lee, M.G. 2012. Pharmacokinetic and pharmacodynamic interaction between nifedipine and metformin in rats: competitive inhibition for metabolism of nifedipine and metformin by each other via CYP isozymes. Xenobiotica, 42(5): 483-495.

Donato, M.T., Jimenez, N., Castell, J.V., and Gomez-Lechon, M.J. 2004. Fluorescence-based assays for screening nine cytochrome P450 (P450) activities in intact cells expressing individual human P450 enzymes. Drug Metab. Dispos. 32(7): 699-706.

El-Sherbeni, A.A., and El-Kadi, A.O. 2014. Characterization of arachidonic acid metabolism by rat cytochrome P450 enzymes: the involvement of CYP1As. Drug Metab. Dispos. 42(9): 14981507.

Gabr, R.Q., Padwal, R.S. and Brocks, D.R. 2010. Determination of metformin in human plasma and urine by high-performance liquid chromatography using small sample volume and conventional octadecyl silane column. J. Pharm. Pharm. Sci. 13(4): 486-494.

Graham, G.G., Punt, J., Arora, M., Day, R.O., Doogue, M.P., Duong, J.K., et al. 2011. Clinical pharmacokinetics of metformin. Clin. Pharmacokinet. 50(2): 81-98.

Hamdy, D.A., and Brocks, D.R. 2011. Effect of hyperlipidemia on ketoconazole-midazolam drug-drug interaction in rat. J. Pharm. Sci. 100(11): 4986-4992.

Hubert, J.C., Wijnberg, J.B.P., and Speckamp, W.N. 1975. Nabh4 Reduction of Cyclic Imides. Tetrahedron, 31(11-1): 1437-1441.

Kajiwara, M., Terada, T., Asaka, J., Ogasawara, K., Katsura, T., Ogawa O., et al. 2007. Critical roles of Sp1 in gene expression of human and rat H+/organic cation antiporter MATE1. Am. J. Physiol. Renal Physiol. 293(5): F1564-1570. 
Kimura, N., Masuda, S., Tanihara, Y., Ueo, H., Okuda, M., Katsura, T., et al. 2005. Metformin is a superior substrate for renal organic cation transporter OCT2 rather than hepatic OCT1. Drug Metab. Pharmacokinet. 20(5): 379-386.

Kobuchi, S., Fukushima, K., Shibata, M., Ito, Y., Sugioka, N., and Takada, K. 2011. Pharmacokinetics of clomipramine, an antidepressant, in poloxamer 407-induced hyperlipidaemic model rats. J. Pharm. Pharmacol. 63(4): 515-523.

Komazawa, H., Yamaguchi, H., Hidaka, K., Ogura, J., Kobayashi, M., and Iseki, K. 2013. Renal uptake of substrates for organic anion transporters Oat 1 and Oat3 and organic cation transporters Oct1 and Oct2 is altered in rats with adenine-induced chronic renal failure. J. Pharm. Sci. 102(3): 1086-1094.

Kristufek, D., Rudorfer, W., Pifl, C., and Huck, S. 2002. Organic cation transporter mRNA and function in the rat superior cervical ganglion. J. Physiol. 543(Pt 1): 117-134.

Lee, M.G., Choi, Y.H., and Lee, I. 2008. Effects of diabetes mellitus induced by alloxan on the pharmacokinetics of metformin in rats: restoration of pharmacokinetic parameters to the control state by insulin treatment. J. Pharm. Pharm. Sci. 11(1): 88-103.

Lee, J.H., Oh, J.H. and Lee, Y.J. 2011. Effects of experimental hyperlipidaemia on the pharmacokinetics of docetaxel in rats. Xenobiotica, 41(9): 797-804.

Lee, J.H., Oh, J.H., and Lee, Y.J. 2012a. Effects of experimental hyperlipidemia on the pharmacokinetics of tadalafil in rats. J. Pharm. Pharm. Sci. 15(4): 528-537.

Lee, Y.S., Kim, Y.W., Kim, S.G., Lee, I., Lee, M.G., and Kang, H.E. 2012b. Effects of poloxamer 407-induced hyperlipidemia on the pharmacokinetics of carbamazepine and its 10,11epoxide metabolite in rats: Impact of decreased expression of both CYP3A1/2 and microsomal epoxide hydrolase. Eur. Neuropsychopharmacol. 22(6): 431-440. 
Lee, Y.S., Yoon, J.N., Yoon, I.S., Lee, M.G., and Kang, H.E. 2012c. Pharmacokinetics of verapamil and its metabolite norverapamil in rats with hyperlipidaemia induced by poloxamer 407. Xenobiotica, 42(8):766-74.

Ma, Y.R., Huang, J., Shao, Y.Y., Ma, K., Zhang, G.Q., Zhou, Y., et al. 2015. Inhibitory effect of atenolol on urinary excretion of metformin via down-regulating multidrug and toxin extrusion protein 1 (rMate1) expression in the kidney of rats. Eur. J. Pharm. Sci. 68(18-26.

Naud J., Michaud J., Beauchemin S., Hebert M.J., Roger M., Lefrancois S., et al. 2011. Effects of chronic renal failure on kidney drug transporters and cytochrome P450 in rats. Drug Metab. Dispos. 39(8): 1363-1369.

Padwal, R.S., Gabr, R.Q., Sharma, A.M., Langkaas, L.A., Birch, D.W., Karmali, S., et al. 2011. Effect of gastric bypass surgery on the absorption and bioavailability of metformin. Diabetes Care, 34(6): 1295-1300.

Patel, J.P., and Brocks, D.R. 2009. The effect of oral lipids and circulating lipoproteins on the metabolism of drugs. Expert Opin. Drug Metab. Toxicol. 5(11):1385-98.

Patel, J.P., Fleischer, J.G., Wasan, K.M., and Brocks, D.R. 2009. The effect of experimental hyperlipidemia on the stereoselective tissue distribution, lipoprotein association and microsomal metabolism of (+/-)-halofantrine. J. Pharm. Sci. 98(7): 2516-2528.

Setter, S.M., Iltz, J.L., Thams, J., and Campbell, R.K. 2003. Metformin hydrochloride in the treatment of type 2 diabetes mellitus: a clinical review with a focus on dual therapy. Clin. Ther. 25(12): 2991-3026.

Shayeganpour, A., Jun, A.S., and Brocks, D.R. 2005. Pharmacokinetics of Amiodarone in hyperlipidemic and simulated high fat-meal rat models. Biopharm. Drug Dispos. 26(6): 249-257. 
Shayeganpour, A., Korashy, H., Patel, J.P., El-Kadi, A.O. and Brocks, D.R. 2008. The impact of experimental hyperlipidemia on the distribution and metabolism of amiodarone in rat. Int. J. Pharm. 361(1-2): 78-86.

Shi, L.Z., Li, G.J., Wang, S., and Zheng, W. 2008. Use of Z310 cells as an in vitro bloodcerebrospinal fluid barrier model: tight junction proteins and transport properties. Toxicol. in vitro, 22(1): 190-199.

Sugioka, N., Haraya, K., Maeda, Y., Fukushima, K., and Takada, K. 2009. Pharmacokinetics of human immunodeficiency virus protease inhibitor, nelfinavir, in poloxamer 407-induced hyperlipidemic model rats. Biol. Pharm. Bull. 32(2): 269-275.

Takizawa, S., Uchide, T., Adur, J., Kozakai, T., Kotake-Nara, E., Quan, J., et al. 2005. Differential expression of endothelin-2 along the mouse intestinal tract. J. Mol. Endocrinol. 35(2): 201-209.

Ter Laak, T., and Baken, K. 2014. The occurrence, fate and ecological and human health risks of metformin and guanylurea in the water cycle - A literature review. KWR, Watercycle Research Institute, Nieuwegein, the Netherlands. $23 \mathrm{pp}$.

Trautwein, C., and Kummerer, K. 2011. Incomplete aerobic degradation of the antidiabetic drug Metformin and identification of the bacterial dead-end transformation product Guanylurea. Chemosphere, 85(5): 765-773.

Wasan, K.M., Brocks, D.R., Lee, S.D., Sachs-Barrable, K., and Thornton, S.J. 2008. Impact of lipoproteins on the biological activity and disposition of hydrophobic drugs: implications for drug discovery. Nat. Rev. Drug Discov. 7(1): 84-99. 


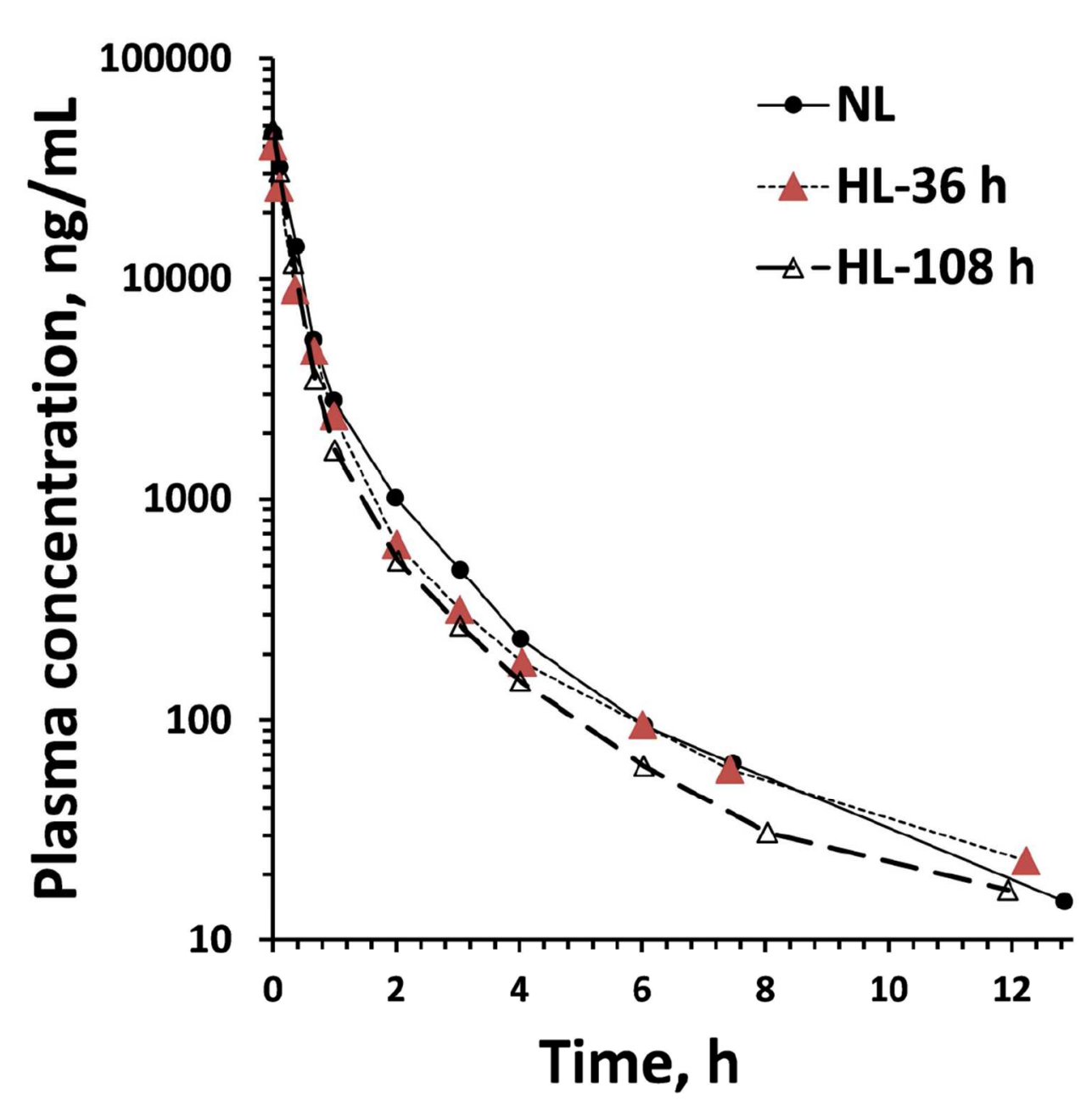

Figure 1: Mean plasma concentration vs. time plots of MET after intravenous administration of $30 \mathrm{mg} / \mathrm{kg}$ as iv doses to normolipidemic $(\mathrm{NL})$ or hyperlipidemic $(\mathrm{HL})$ rats.

$105 \times 104 \mathrm{~mm}(300 \times 300 \mathrm{DPI})$ 


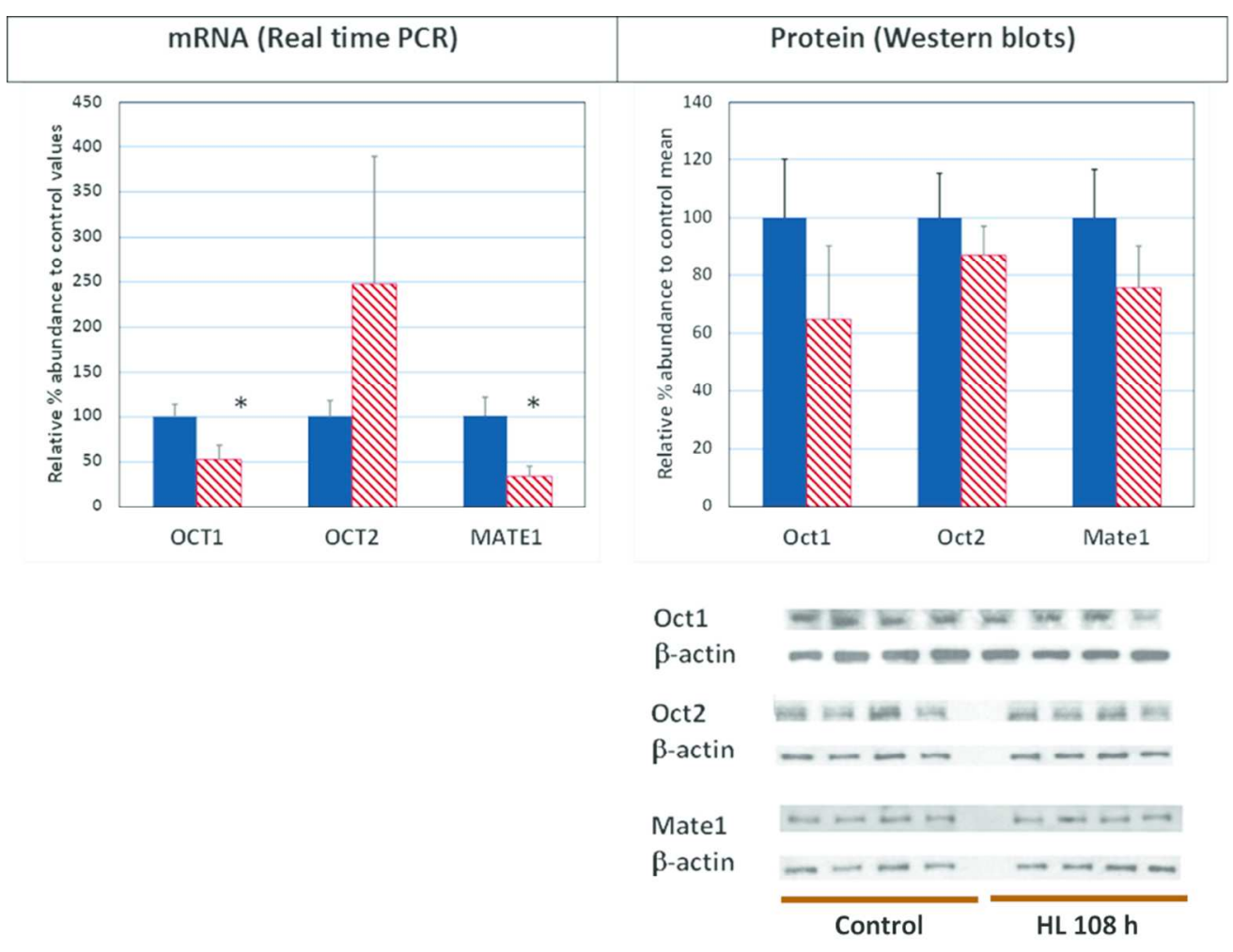

Figure 2: Effect (mean $\pm \mathrm{SD}$ ) of $\mathrm{HL}$ after $108 \mathrm{~h}$ ip injection of $\mathrm{P} 407$ on the mRNA and protein expression of rat kidney OCT1, OCT2 and MATE1 ( $n=4$ /group). Solid bars indicate control NL rats, cross hatched bars indicate treatment HL rats. Significant differences of $\mathrm{HL}$ from NL are denoted by *.

$96 \times 77 \mathrm{~mm}(300 \times 300 \mathrm{DPI})$ 

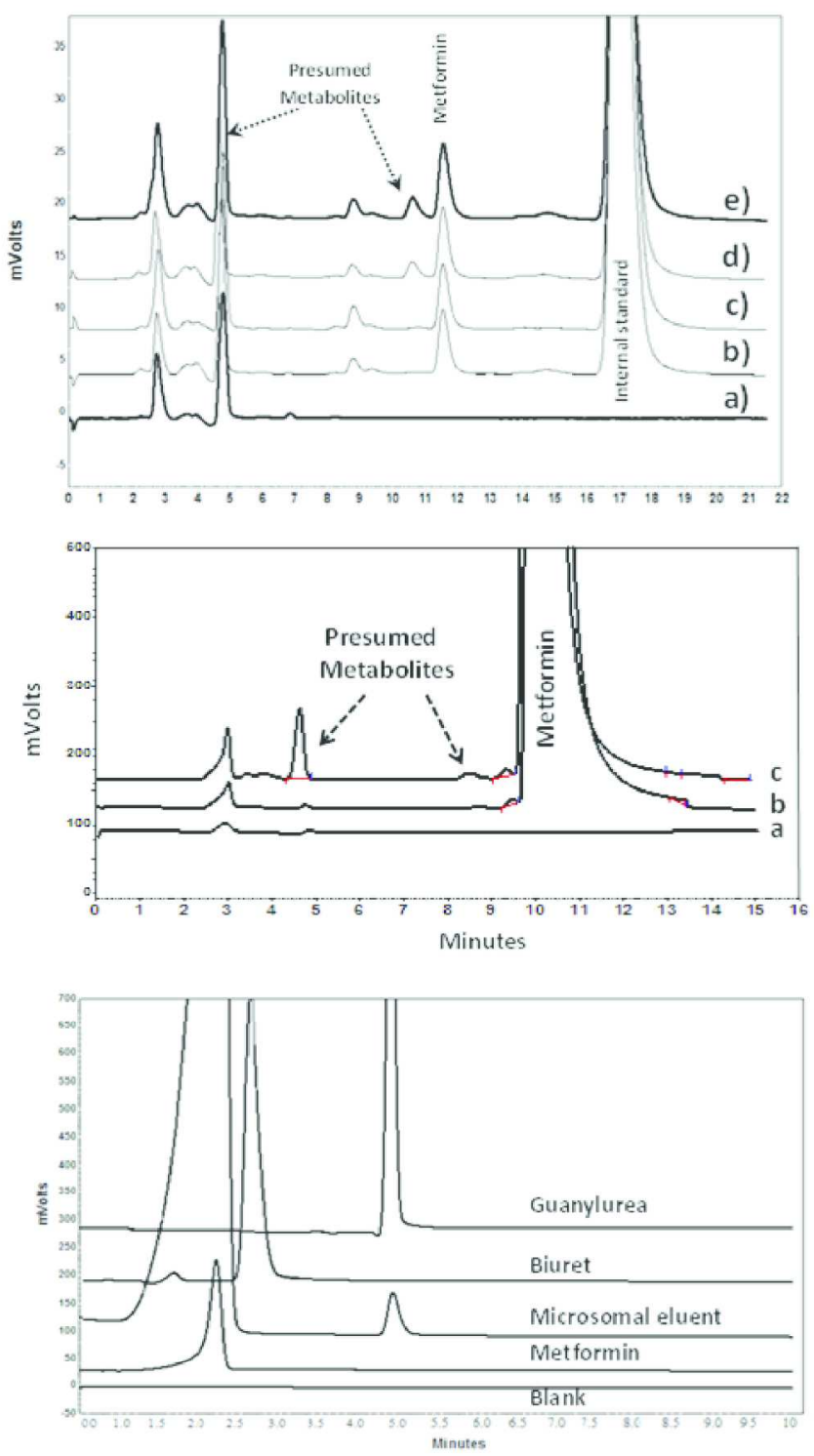

Figure 3. Top panel: Effect of hepatocytes on MET metabolism after exposure to $1000 \mathrm{ng} / \mathrm{mL}$ MET. Representative HPLC-UV chromatograms are depicted for a) hepatocyte-free media for $24 \mathrm{~h}, \mathrm{~b}) \mathrm{hepatocyte-}$ free media containing $1000 \mathrm{ng} / \mathrm{mL}$ MET for $24 \mathrm{~h}$, and hepatocytes exposed to MET for c) $0 \mathrm{~h}$, d) $12 \mathrm{~h}$, and e) $24 \mathrm{~h}$. Middle panel: Chromatogram depicting a) MET-free microsomal protein, b) MET in buffer without microsomal protein, and c) microsomal incubation with MET $100 \mu \mathrm{g} / \mathrm{mL}$ for $30 \mathrm{~min}$. Lower panel: Chromatograms showing direct injection of standard solutions of guanylurea $(1 \mu \mathrm{g} / \mathrm{mL})$, biuret $(1 \mu \mathrm{g} / \mathrm{mL})$ and MET $(50 \mathrm{ng} / \mathrm{mL})$ and the collected eluent of the peak eluting at $4.8 \mathrm{~min}$ in the microsomal incubation using the modified mobile phase. The blank is the extracted microsomal media without addition of MET.

$141 \times 237 \mathrm{~mm}(300 \times 300 \mathrm{DPI})$ 


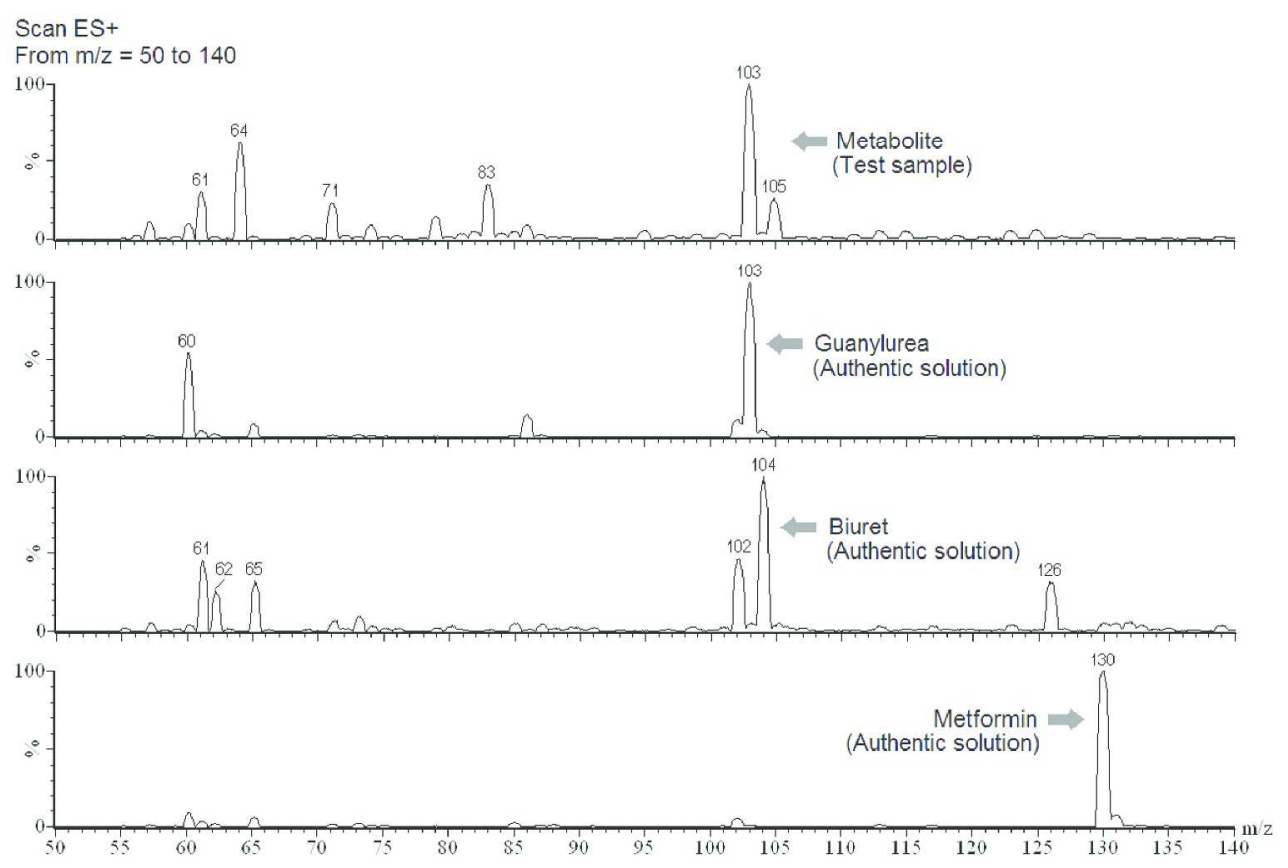

Figure 4: Mass spectra and chemical structures, from top down, MET-metabolite eluent fraction, guanylurea, biuret and MET. All compounds were dissolved or reconstituted in double distilled water containing $1 \%$ formic acid. The major ion of m/z 103 matched that of guanylurea.

$215 \times 148 \mathrm{~mm}(300 \times 300$ DPI) 


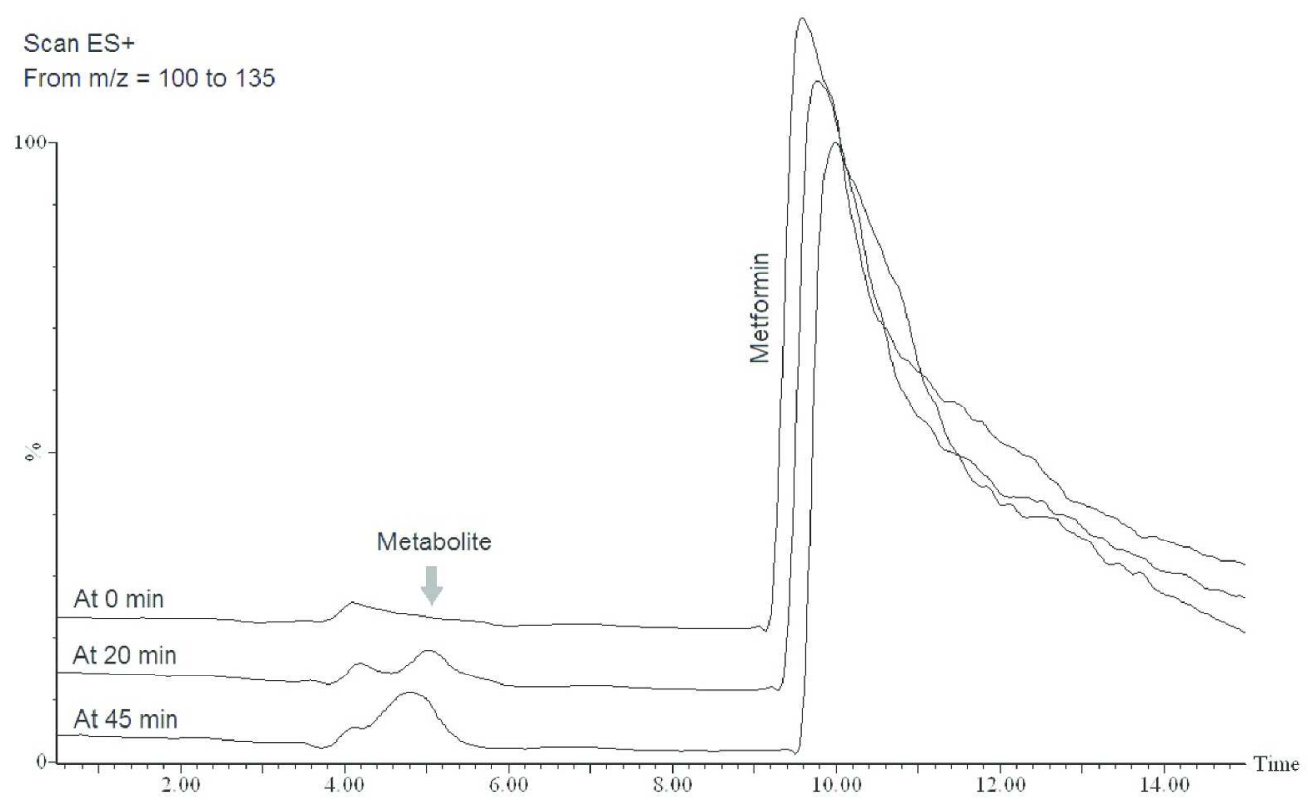

Figure 5: Mass spectral chromatograms of injection of MET after exposure to rat microsomal protein for 0 , 20 and $45 \mathrm{~min}$ (ion scan from m/z 100 to 135.). The MET eluted at 10 min under these conditions. A peak appeared with progression of incubation times at $5 \mathrm{~min}$, which corresponded with the elution time of guanylurea (indicated as control injection containing guanylurea and metformin standards in the same sample).

$200 \times 123 \mathrm{~mm}(300 \times 300$ DPI $)$ 